\title{
Topology Assessment for 3+3 Terminal Offshore DC Grid considering DC fault management
}

\begin{tabular}{|r|l|}
\hline Journal: & IET Generation, Transmission \& Distribution \\
\hline Manuscript ID: & GTD-2013-0838.R1 \\
\hline Manuscript Type: & Research Paper \\
\hline Date Submitted by the Author: & n/a \\
\hline Complete List of Authors: & $\begin{array}{l}\text { Jovcic, Dragan; University of Aberdeen, Engineering; } \\
\text { Taherbaneh, Mohsen; University of Aberdeen, Engineering } \\
\text { Taisne, Jean pierre; RTE, CNER } \\
\text { NGUEFEU, Samuel; RTE, CNER }\end{array}$ \\
\hline Keyword: & POWER SYSTEMS, POWER TRANSMISSION, WIND POWER \\
\hline
\end{tabular}

SCHOLARONE $^{m}$

Manuscripts 


\title{
Topology Assessment for 3+3 Terminal Offshore DC Grid considering DC fault management
}

\author{
Dragan Jovcic ${ }^{1}$, Mohsen Taherbaneh ${ }^{1}$, Jean Pierre Taisne ${ }^{2}$, Samuel Nguefeu ${ }^{2}$ \\ ${ }^{1}$ School of Engineering, University of Aberdeen, Aberdeen, UK \\ ${ }^{2}$ RTE, France
}

\begin{abstract}
This paper assesses 4 DC grid topologies where each of the terminals can exchange power with any other terminal and a DC fault on any DC cable can be isolated. The DC grids are built using the following components: Hybrid DC Circuit Breakers (CB), Mechanical DC CBs, DC/DC converters and DC hubs. The aim is to compare DC fault performance, technical feasibility/readiness, power transfer security, expansion and costs. The base case for comparison are 3 separate $300 \mathrm{~km}$ offshore HVDCs connecting $31 \mathrm{GW}$ offshore wind farms with 3 onshore VSC terminals. The rating of DC CBs is limited by the state of technology and costs which introduces limitation on the length of DC cables (because of communication delays) and on the DC bus fault level (limiting the number of connecting DC lines). DC/DC converters inherently block propagation of DC faults and their rating is not sensitive to DC fault level. DC hubs have considerable cost advantages over multiple DC/DC converters in case where multiple DC systems are connecting at the same DC station. The cost assumptions for all major components are analysed including the offshore platform costs. The study concludes that overall DC grid costs are similar (within 8\%) for all 4 topologies. While power security is similar for all technologies, the expansion options are best with DC/DC converters or DC hubs. DC hubs nevertheless suffer from highest on-state losses.
\end{abstract}

\section{Introduction}

The main motivation and interest for DC grids comes from the development of offshore wind power which cannot be connected using AC grids, and the advances in VSC HVDC including latest Modular Multilevel Converters [1]. The backbone of future European super grid will be constructed based on DC grid.

The development of DC grid is among the most significant technical challenges in power engineering. The DC grids are built by interconnecting multiple DC transmission lines, which demands considerable technical advances since currently only point-to-point HVDC exist. New components and systems are required for developing grid protection but also the grid topologies are uncertain.

With AC systems, the grid fault management practices are adequate to support any grid topology that system architects may develop, and without much cost implications. However with DC networks the fault isolation is much more challenging, it requires much more expensive components and complex protection systems [1]-[4]. As DC cables have very small resistance without any reactance $(f=0)$, the DC faults will cause widespread voltage collapse in the grid and the fault currents will be large. DC fault currents have no zero crossings and therefore require costly semiconductor circuit breakers. In addition, the existing DC transmission systems 
are designed by different suppliers with different control/protection strategies and perhaps different DC voltage levels causing challenges to coordinate DC systems from different vendors. The feasibility of DC grid topologies will largely depend on the cost of protection systems.

Ref [1] studies technical feasibility of a multi-terminal VSC-HVDC grid in the North Sea, connecting several offshore wind farms to several onshore AC substations. Results demonstrated the ability to control wide range of complex multi-terminal HVDC topologies in case of severe power variations. The DC grid protection system is based on semiconductor/hybrid DC CBs and it is developed in more depth in [5], however the component ratings or costs are not examined. The hybrid DC CBs are in prototype stage [6], and this article will attempt to assess their required rating and costs but also the cost-effectiveness of DC grid topologies based on these components.

In Ref. [2], several multi-terminal DC grid topologies were proposed based on DC/DC converters and performance analyzed. The mechanical DC CBs which have been studied in 80's [7], have been proposed as low cost solution if DC grids employ fault tolerant DC/DC converters [8], which can significantly reduce DC fault currents. However detailed dc grid studies related to performance, ratings and cost studies have not been reported.

Because of costs and losses, DC/DC converters may not be suitable for connecting multiple DC lines to a single DC bus. A multiport version of DC/DC converter called DC hub, has also been developed and it enables connection of multiple DC lines of different vendors and retains excellent DC fault tolerance [9].

This paper develops and evaluates three approaches in building DC grid capable of DC fault management; 1) topologies with only DC circuit breakers, 2) topologies with DC CBs and DC/DC converters and 3) topologies with DC-hubs. We will start with 3 offshore and 3 onshore VSC terminals at a fixed location and develop a number of DC grid topologies capable of power exchange between any terminals and capable of clearing a DC fault on any DC cable.

\section{Main DC grid components and costs}

A DC grid includes several main components which depend on chosen topology: VSC converters, DC/DC converters, DC hub, hybrid DC CBs and DC cables. The cost of offshore platforms is considered since different topologies require different number of platforms and different sizes. The study deals only with the transmission system and therefore wind farm costs will not be included.

\subsection{VSC converter}

The costs for a $1 \mathrm{GW}$ VSC converter is given as $110 M \epsilon$ and it is presumed that cost is proportional to the converter rating [10],[11]. 


\subsection{Hybrid DC CB}

A hybrid DC CB consists of the following components [6]: 1) Main semiconductor valve which is normally open and is rated for interrupting DC fault current and for full DC voltage. 2) Auxiliary semiconductor valve with surge arrester which is normally on taking nominal DC current, rated for interrupting fault DC fault current but for very low voltage. 3) Mechanical CB which is normally closed and rated for nominal DC current and for full DC voltage with zero breaking duty. 4) High-power energy dump.

It is very difficult to determine the rating (and therefore costs) of the $\mathrm{DC} \mathrm{CB}$, since the interrupting current is dependent on the $\mathrm{AC}$ grid impedance, on the number of connecting DC lines (grid topology) but also on the speed of the protection system.

We propose to link the DC CB cost with the VSC converter costs, and the number of infeed DC lines using the term DC fault level. Figure 1 shows a single VSC converter feeding to a DC bus with a hybrid DC Circuit Breaker. As AC grid short circuit level (SCL) and short circuit ratio (SCR) are usually given, the DC fault current will be expressed using nominal DC current and SCR.

\section{Figure 1. VSC connected to a single DC line with DC CB}

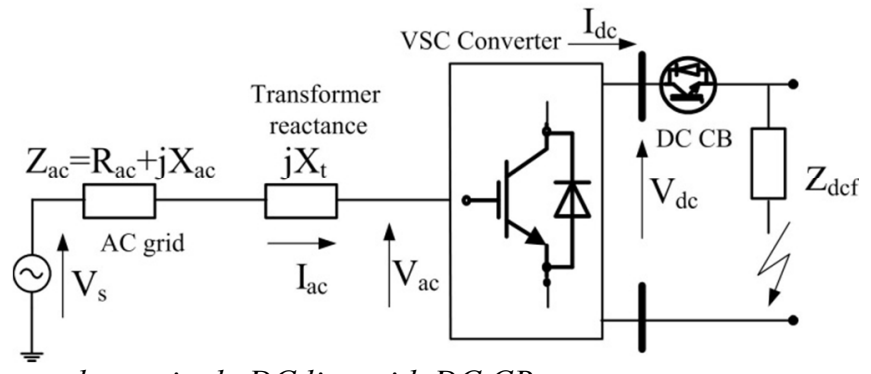

During normal operation the line-line magnitude of AC side converter voltage $\mathrm{V}_{\mathrm{acm}}$ is given as the function of DC voltage $\mathrm{V}_{\mathrm{dc}}$ :

$V_{a c m}=M_{m} \sqrt{\frac{3}{2}} \frac{V_{d c}}{2}$

For simplicity the modulation index at full power is assumed as $M_{m}=1$. Assuming that normally $V_{s m}=V_{a c m}$, the short circuit level is:

$S C L=\frac{V_{a c m}^{2}}{z_{a c m}}$

Where $z_{a c m}=z_{a c} l$ and therefore the short circuit ratio is [12]:

$S C R=\frac{S C L}{P_{d c}}=\frac{S C L}{V_{d c} I_{d c}}$

Therefore using (1) and (3) the DC current at rated power is: 
$I_{d c}=\frac{S C L}{S C R V_{d c}}=\frac{S C L \sqrt{3}}{S C R 2 \sqrt{2} V_{a c m}}$

For a DC fault, IGBTs will be tripped and VSC converter becomes a diode bridge. Assuming that diode bridge AC current is in phase with AC voltage, we can get the AC fault current:

$$
I_{a c f}=\frac{V_{s d}+j V_{s q}-V_{a c m}}{z_{a c}+j X_{t}}
$$

where $X_{t}$ is transformer, $V_{s d}$ and $V_{s q}$ are the two components of $V_{s}$ phasor, and coordinate frame is linked with converter voltage $V_{a c}=V_{a c m}$. A relation between $\mathrm{AC}$ and $\mathrm{DC}$ voltages in a diode bridge is [12]:

$$
V_{d c}=\frac{3 \sqrt{2}}{\pi} V_{a c m}
$$

The diode bridge DC current can be obtained using power balance equation and (6):

$$
I_{d c f}=\pi / \sqrt{6} I_{a c f}
$$

Considering next the following assumptions:

- Magnitude of remote source is constant: $V_{s m}=I V_{s} I=$ const.

- Diode bridge current is in phase with voltage $I_{a c f m}=I_{a c f}$. In practice diode curerrent will be lagging voltage by $5-10^{\circ}$, but the impact of this lag is negligible comparing with AC grid impedance,

- DC fault has a finite resistance $z_{d c}$, and therefore DC voltage is $V_{d c}=z_{d c f} * I_{d c f}$,

Using (5)-(7) the DC fault current can be obtained:

$$
I_{d c f}=\frac{\pi V_{s m}}{\sqrt{6} \sqrt{R_{a c}^{2}+\left(X_{a c}+\mathrm{X}_{\mathrm{t}}\right)^{2}+\frac{\pi^{4}}{108} z_{d c f}^{2}+2 R_{a c} z_{d c f} \frac{\pi^{2}}{3 \sqrt{12}}}}
$$

If $z_{d c f}=0$, and assuming that transformer rating is same as DC power, from (8) we get: 


$$
I_{d c f}=\frac{\pi S C L}{\sqrt{6} \sqrt{3} V_{a c m}\left(1+S C R X_{t p u}\right)}
$$

Where $X_{t p u}$ is transformer $p u$ reactance. The above equation is also accurate for non-zero fault resistance (even with long DC cables) since AC impedance is considerably larger. Dividing (8) by (4) we get DC fault current in $p u$ (relative to DC rated current):

$$
I_{d c f p u}=\frac{2 \pi S C R}{3 \sqrt{3}\left(1+S C R X_{t p u}\right)}
$$

The values for SCR will vary typically $2<S C R<20$, and therefore the steady-state DC fault current can be calculated from the above formula, as shown in Figure 2. As the SRC is increasing the fault current is increasing, although some adjustment is possible by varying the transformer impedance (or series reactor). The manufacturers will not allow too high fault current since VSC freewheeling diodes should be able to withstand short circuit current for 20-30ms [11].

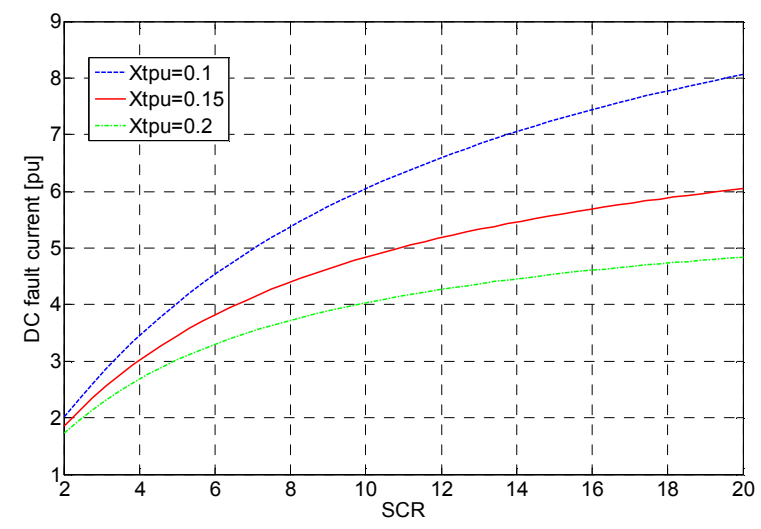

Figure 2. DC fault current as the function of AC system SCR.

The DC fault current will have a transient peak which might reach 2 times the steady-state value shown in Figure 2 in the first 1050ms [13]. There is also a capacitor discharge component in first few ms with $2 / 3$ level converter but it does not exist with modern Modular converters. On the other hand the DC circuit breakers will have internal series inductors which will limit the slope of DC fault current [6] and transiently reduce fault current. Therefore from Figure 2 we can reasonably expect that DC CB interrupting current for a single VSC will be in the range of 5-10pu. These fault currents are within the one-off from cold turn-off current for a single IGBT and the first prototypes have demonstrated $7 k A$ interrupting capability [6]. Note also that a DC CB should be rated for full DC voltage which is same as the rating of any valve inside the VSC converter. 
Manufacturers are aiming to have a standardized 7-valve converter (VSC plus DC CB) capable of clearing DC faults. This implies that DC CB main valve rating is same as one valve of the connecting VSC converter and therefore the cost is expected to be around 1/6th of the VSC semiconductor costs. Adding further costs for energy dump, mechanical and auxiliary switch, possibly new valve hall, we assume that total DCCB cost is $28 \%$ of VSC costs for the same DC voltage and rated current.

In case that multiple VSCs are connected to a DC bus, the fault current will be the sum of infeeds from all VSC (diode) converters. We can define total DC fault current for a DC bus with $p$ VSC converters (and similarly DC fault level) using (10):

$$
I_{d c f_{-} \text {bus }}=\sum_{i=1}^{p} \frac{2 \pi S C R_{i}}{3 \sqrt{3}\left(1+S C R_{i} X_{t p u_{-} i}\right)} I_{d c_{-} i}
$$

\subsection{Mechanical DC CB}

A mechanical DC CB consists of the following components [7]: 1) main and auxiliary circuit breakers which are similar to common AC circuit breakers. They are rated for full DC voltage and peak interrupting current. 2) ZnO surge arrester and 3) resonant circuit which generates AC current when auxiliary circuit breaker is closed. This AC current is superimposed on the main DC current in order to create current zero crossings in the main circuit breaker. The cost is of a similar magnitude as mechanical AC CBs, which is presumed to be $0.3 \mathrm{M} €$ for $1 G W$ unit, and it is proportional to the voltage and the fault current.

\subsection{DC/DC converter and DC hub}

The LCL DC/DC converters have been proposed for DC grids in [8], but most other DC/DC technologies like dual active bridge DC/DC converters will have similar components, ratings and performance. The main characteristics of DC/DC converters are:

- They do not propagate DC faults. Generally, there are no high currents in the DC/DC converter during DC fault conditions. DC/DC converter rating is not dependent on DC fault level. There is no DC voltage collapse on the unfaulted side.

- They provide DC voltage stepping and potentially connect different DC systems of different manufacturers,

- They provide fast power flow control,

- They have operating losses which will be around $2 \%$.

The DC hub is developed as a multiport version of a DC/DC converter [9]. It is based on multiple AC/DC IGBT converters and an internal passive LCL circuit but no internal AC transformers. It is capable of connecting multiple DC transmission lines with different DC voltages. It retains good DC fault properties as DC/DC converters. A fault on any DC line will not be transferred to other DC lines and the hub will normally operate. The cost for DC/DC converter and a DC hub is assumed to be $90 M €$ per port (per AC/DC bridge). 


\subsection{Wind farms}

In our study, it is assumed that wind farm uses Permanent Magnet (PM) generators with fully rated converters. Hence, the wind farm fault current can be controlled to around rated value [14]. A wind farm with doubly fed induction generators will have similar fault current magnitudes in the first 10-20ms.

\subsection{DC cable costs}

The DC cable costs are known from several recent projects [10], and it is concluded that the costs are proportional to power rating and length. They are assumed as $0.001490 \mathrm{M} / \mathrm{MW} / \mathrm{km}$. The DC cable impedances will be neglected in this fault study for simplicity.

\subsection{Offshore Platform costs}

References $[3,10]$ conclude that the cost estimation for offshore DC platform, able to support a $1000 \mathrm{MW}$ VSC converter including installation, is about $150 \mathrm{M} €$. Reference [10] implies that the platform costs are dependent primarily on the weight and size of the topside. In the studied topologies, the platforms for new components like DC CBs, DC/DC converters and DC-hubs need to be considered. Costs for these platforms can be estimated based on offshore VSC platform cost, and using the following formula:

$$
\text { Component } \text { splatformcost }=\text { offshoreVSCplatformcost } \times a \times b
$$

where $a$ is the size ratio (the ratio of size of new component to the size of offshore VSC converter) and $b$ is weight ratio (the ratio of weight of new component to the weight of offshore VSC converter). The component size is generally proportional to the power rating, however the weight is largely dependent on the magnetic components.

Table 1 summarizes the costs for all components in this study.

Table 1: Assumed DC grid component costs

\begin{tabular}{|c|c|c|c|c|}
\hline \multicolumn{2}{|l|}{ Component } & Cost (ME/MW) & Cost for 1GW & Comments \\
\hline \multicolumn{2}{|c|}{$\mathrm{AC} / \mathrm{DC}$ VSC converter } & 0.11 & $110 \mathrm{M} €$ & \\
\hline \multicolumn{2}{|c|}{ Hybrid DC CB (unidirectional) } & 0.03 & $30 \mathrm{M} €$ & 1 valve out of 6 in a VSC. \\
\hline \multicolumn{2}{|c|}{ Mechanical DC CB } & 0.0003 & $0.3 \mathrm{M} €$ & \\
\hline \multicolumn{2}{|l|}{ DC/DC converter } & 0.18 & $180 \mathrm{M} €$ & 2 VSC converters \\
\hline \multicolumn{2}{|c|}{ DC-hub (IGBT-based converter) } & 0.09 /port & $90 \mathrm{M} € /$ port & \\
\hline \multirow{4}{*}{$\begin{array}{l}\text { Offshore platform } \\
\text { for }\end{array}$} & VSC (wind farm) & 0.15 & $150 \mathrm{M} €$ & \\
\hline & hybrid DC CB & 0.0203 & $20.3 \mathrm{M} €$ & $\mathrm{a}=0.03 / 0.11=0.27, \mathrm{~b}=0.5$ (no transformer) \\
\hline & $\mathrm{DC} / \mathrm{DC}$ & 0.1968 & $196.8 \mathrm{M} €$ & $\mathrm{a}=0.18 / 0.11=1.64, \mathrm{~b}=0.8$ (two inductors) \\
\hline & DC-hub & $0.0984 /$ port & 98.4 M€/port & $\mathrm{a}=0.09 / 0.11=0.82, \mathrm{~b}=0.8$ (per port) \\
\hline \multicolumn{2}{|l|}{ DC cable (pair) } & $0.0014 / \mathrm{km}$ & $140 \mathrm{M} €($ for $100 \mathrm{~km})$ & \\
\hline
\end{tabular}




\section{Base case (Topology 1)}

Figure 1 shows the base case connection in this study, connecting $31 G W$ onshore VSC terminals with $31 G W$ offshore wind farms using 3 separate HVDCs. It is assumed that direct distance between onshore AC substations and offshore wind farms is $300 \mathrm{~km}$ while distance between the wind farms and between onshore VSCs is $100 \mathrm{~km}$. The same location of terminals will be used for all cases in this study. The DC faults are cleared using AC side circuit breakers as with any VSC HVDC system.

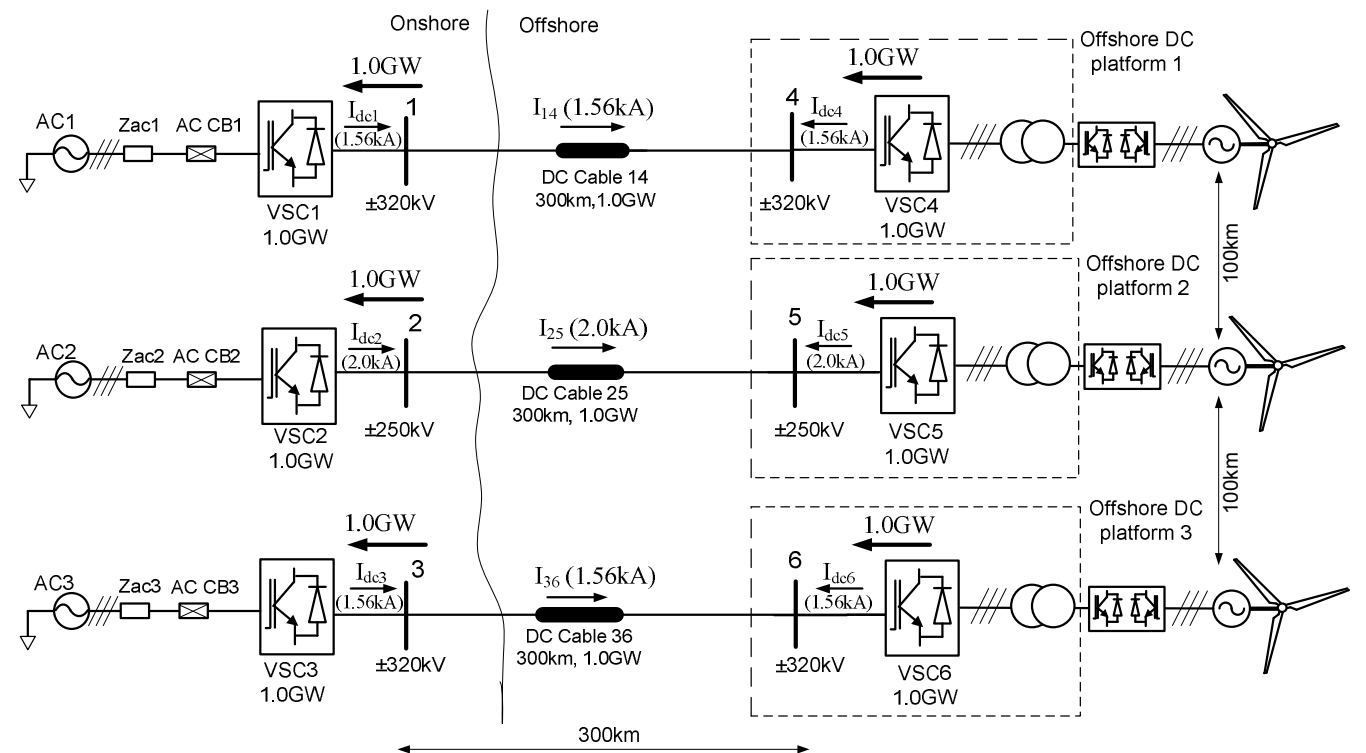

Figure 3. $\quad 3+3$ connection using 3 HVDCs, base case (topology 1)

The main drawbacks of topology 1 are: power exchange is possible only between specific pairs of terminals (a wind farm can trade power with only one onshore VSC), an onshore VSC terminal cannot trade power with any other onshore VSC terminal and a DC cable fault implies that 2 terminals are lost (cannot trade power). The main advantages are; the three systems are separate and can use different ratings and components but also faults on one system will not affect the other systems. Table 2 shows the summary of costs.

Table 2: Cost estimation for the Base case (topology 1)

\begin{tabular}{|l|l|l|l|}
\hline \multicolumn{1}{|c|}{ Items } & \multicolumn{1}{c|}{ Numbers and Rated } & Cost estimation/unit & Cost estimation \\
\hline AC/DC VSC converter & $3(1.0 \mathrm{GW})+3(1.0 \mathrm{GW})$ & $110 \mathrm{M} €$ & $660 \mathrm{M} €$ \\
\hline Offshore platform 1 & VSC $(1.0 \mathrm{GW})$ & $150 \mathrm{M} €$ & $150 \mathrm{M} €$ \\
\hline Offshore platform 2 & VSC $(1.0 \mathrm{GW})$ & $150 \mathrm{M} €$ & $150 \mathrm{M} €$ \\
\hline Offshore platform 3 & VSC $(1.0 \mathrm{GW})$ & $150 \mathrm{M} €$ & $150 \mathrm{M} €$ \\
\hline DC cable (pair) & $3(1.0 \mathrm{GW}$, offshore) $300 \mathrm{~km}$ & $1.4 \mathrm{M} € / \mathrm{GW} / \mathrm{km}$ & $1260 \mathrm{M} €$ \\
\hline \multicolumn{3}{|c|}{ Total Cost to transmit $3 \mathrm{GW}$} & $2370 \mathrm{M} €$ \\
\hline \multicolumn{3}{|c|}{ Total cost per GW } & $790 \mathrm{M} € / \mathrm{GW}$ \\
\hline
\end{tabular}




\section{Meshed 3+3 DC grid with hybrid DC CBs (Topology 2)}

Figure 4 shows meshed DC grid with hybrid DC CBs for connecting same VSC terminals (same location and ratings) as in topology 1. The protection method is based on [5], which includes a DC CB at the ends of each cable and a communication link between DC CBs on each cable (no communication is required between cables). The current sensors must be sensitive to current direction. Each DC fault is isolated with a pair of $\mathrm{DC} \mathrm{CBs}$ or a $\mathrm{DC} \mathrm{CB}$ and an $\mathrm{AC} \mathrm{CB}$. The protection plan also suggests using additional DC circuit breakers at the converter side of each DC bus for back-up protection. The rating of all VSC terminals and DC cables are 1.0GW and rating for DC CBs and other components are shown in the figure.

The main advantages of this topology include: each terminal can trade power with any other (within cable ratings) and the on-state losses in the hybrid DC CBs are negligible. Also this topology can be developed into a fully meshed grid with n-1 security. The primary issues are:

- Grid-wide protection system coordination, which relies on pilot wire communication between DC CBs on each DC line. This is a dispersed system with many components and therefore reliability will be low.

- The DC fault current magnitude depends on the number of connecting VSCs. Expansion by adding new VSC converters will be difficult since all DC CBs should be uprated. Even if higher rated DC CBs are developed in the future their costs will be high.

- The fault current magnitude will depend on the line length. The communication delay (1-5ms depending on line length) and processing logic time are big issues since they will indirectly imply larger interrupting currents for DC CBs. Long DC lines will be problem. Also, if the two DC CBs on a line are not tripped simultaneously, the last DC CB to trip will experience higher current.

- During each DC fault the whole DC grid collapses (0 DC voltages on all busses). Assuming that DC fault is successfully isolated, the transient recovery to full DC voltage on all terminals may become a challenge. There is also a serious consequence in case that protection system fails to operate.

- All DC busses must have same nominal DC voltage. Furthermore, all DC equipments (VSC converters, DC CBs, control and protection and ...) must be standardised and compatible between various terminals. Multivendor DC grid will be a challenge. 


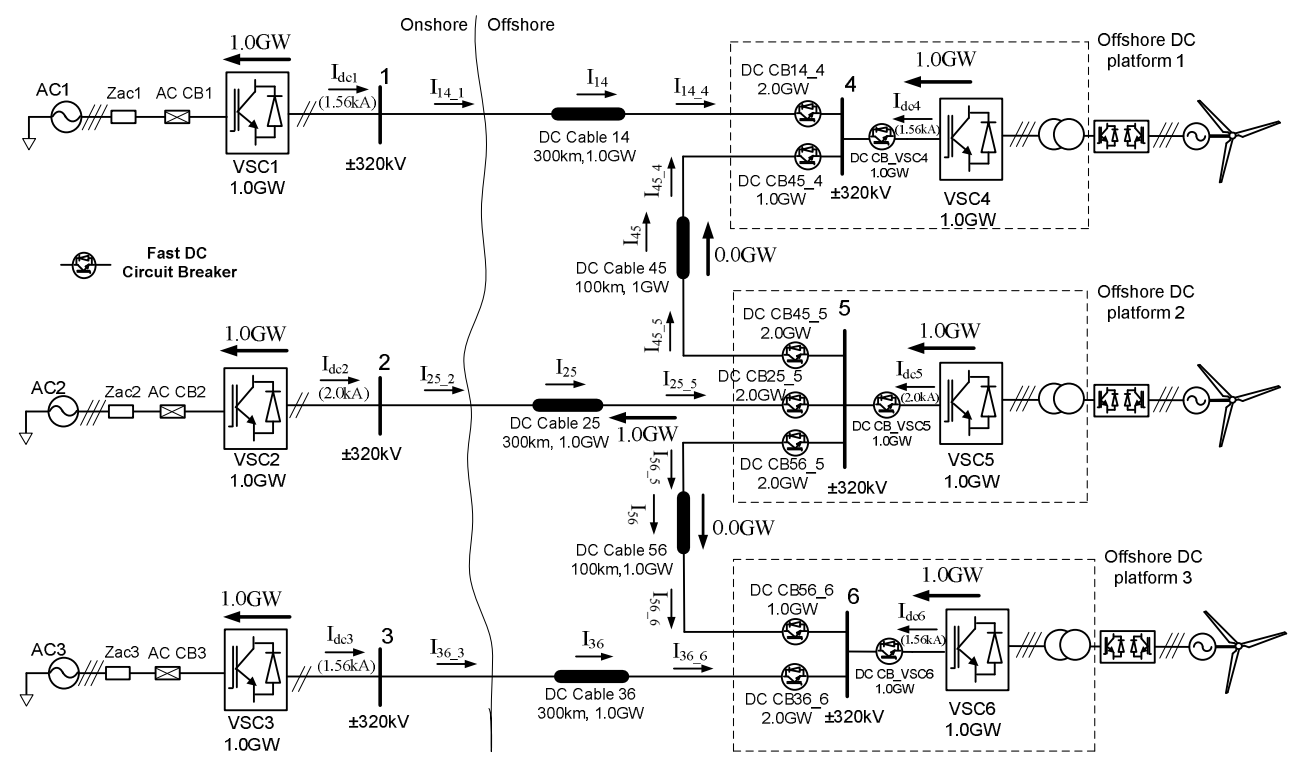

Figure 4. $\quad 3+3$ terminals DC grid with hybrid DC CBs (topology 2)

Table 3 shows current levels in each DC cable and DC CB during a fault on two cables (cables 14 and 45), and prior to fault isolation. The notation $1 \mathrm{fpu}$ means DC fault current for a given SCR which can be determined from Figure 1. It is noted that multiple DC CBs experience infeeds from 2 VSC converters (2fpu), which can be very high. From these results it is also emerging that the available rating of DC CBs will limit the number of DC lines that can be connected to a DC bus.

Table 3: Topology 2 DC fault currents for cable fault

\begin{tabular}{|c|c|c|}
\hline & \multicolumn{2}{|c|}{ Fault on the cable } \\
\hline Fault current & \begin{tabular}{|l|} 
Cable 14 \\
\end{tabular} & Cable 45 \\
\hline Cable 14 (I14) & $\begin{array}{l}\mathrm{I} 14 \_1=1 \mathrm{fpu}, \\
\mathrm{I} 14 \_4 \approx \mathbf{2 f p u}\end{array}$ & $\begin{array}{l}\mathrm{I} 14 \_1=1 \mathrm{fpu}, \\
\mathrm{I} 14-4=1 \mathrm{fpu}\end{array}$ \\
\hline Cable 25 (I25) & $\begin{array}{l}\mathrm{I} 25 \_2=1 \mathrm{fpu} \\
\mathrm{I} 25-5=1 \mathrm{fpu}\end{array}$ & $\begin{array}{l}\mathrm{I} 25 \_2=1 \mathrm{fpu}, \\
\mathrm{I} 2555=1 \mathrm{fpu}\end{array}$ \\
\hline Cable 36 (I36) & $\begin{array}{l}36 \_3=1 \mathrm{fpu}, \\
\mathrm{I36 \_ 6}=1 \mathrm{fpu}\end{array}$ & $\begin{array}{l}36 \_3=1 \mathrm{fpu}, \\
\mathrm{I} 36 \_6=1 \mathrm{fpu}\end{array}$ \\
\hline Cable 45 (I45) & $\begin{array}{l}\mathrm{I} 4554 \approx 1 \mathrm{fpu}, \\
\mathrm{I} 45 \_5 \approx \mathbf{2 f p u}\end{array}$ & $\begin{array}{l}\text { I45_4 } 4 \approx 1 \mathrm{fpu}, \\
\text { I45_5 } 5 \approx \mathbf{2 f p u}\end{array}$ \\
\hline Cable 56 (I56) & $\begin{array}{l}56 \_5 \approx 1 \mathrm{fpu}, \\
\text { I56_6 } \approx 1 \mathrm{fpu}\end{array}$ & $\begin{array}{l}56 \_5 \approx 1 \mathrm{fpu}, \\
\text { I56_6 } \approx \approx 1 \mathrm{fpu}\end{array}$ \\
\hline
\end{tabular}

The post fault topology may imply loss of capacity depending on the location of the fault. After a fault on cable 14, DC circuit breaker "DC CB14_1" and AC CB1 will open and isolate the faulted cable from the grid. As the AC substations are optimally rated $(1.0 \mathrm{GW})$, there will be $1.0 \mathrm{GW}$ loss in capacity and the grid can only transfer $2 \mathrm{GW}$ from offshore. Therefore, VSC4-6 will each reduce its generated power by $1 / 3$. For the fault on cable 25 and 36, the conclusions are similar. After a fault on cable 45 , DC circuit breakers "DC CB45_4" and "DC CB45_5" will open and isolate the faulted cable from the grid. There is no loss in capacity in the grid, but this 
would lead to "alert state" since any further fault would imply significant loss in capacity. For the fault in cable 56 , there is a similar situation.

On the positive side, adding a new meshed line (say line 23) significantly increases reliability and power transfer security of this topology without the need for upgrading existing DC CBs. Such a new line would entail 6 new DC CBs, at a cost similar to two VSCs.

Direct investment cost for topology 2 includes converters, cables, hybrid DC circuit breakers and offshore DC platforms, as shown in Table 4. The estimation gives $1135 \mathrm{M} €$ as total cost per GW for this topology, which is $43 \%$ over the cost of the topology 1 .

Table 4: Cost estimation for topology 2

\begin{tabular}{|c|c|c|c|}
\hline Items & Numbers and Rated & Cost estimation M€/unit & Cost estimation \\
\hline AC station with all equipments & $3(1 \mathrm{GW})+3(1 \mathrm{GW})$ & 110 & $660 \mathrm{M} €$ \\
\hline Offshore VSC platform 1 & $\mathrm{VSC}+2 \times \mathrm{DC} C \mathrm{CB}(1 \mathrm{GW})+1 \times \mathrm{DC} C \mathrm{CB}(2 \mathrm{GW})$ & $150+2 \times 20.3+1 \times 40.6$ & $231 \mathrm{M} €$ \\
\hline Offshore VSC platform 2 & $\mathrm{VSC}+2 \times \mathrm{DC} C \mathrm{CB}(2 \mathrm{GW})$ & $150+1 \times 20.3+3 \times 40.3$ & $272 \mathrm{M} €$ \\
\hline Offshore VSC platform 3 & $\mathrm{VSC}+2 \times \mathrm{DC} C \mathrm{CB}(1 \mathrm{GW})+1 \times \mathrm{DC} C \mathrm{CB}(2 \mathrm{GW})$ & $150+2 \times 20.3+1 \times 40.6$ & $231 \mathrm{M} €$ \\
\hline \multirow{2}{*}{ DC Cable (pair) } & $3(1 \mathrm{GW}, 300 \mathrm{~km})$ & \multirow{2}{*}{$0.0014 / \mathrm{km}$} & $1260 \mathrm{M} €$ \\
\hline & $2(1 \mathrm{GW}, 100 \mathrm{~km})$ & & $280 \mathrm{M} €$ \\
\hline \multirow{2}{*}{ Hybrid DC circuit breaker } & $5(1 \mathrm{GW})$ & \multirow{2}{*}{$0.03 / \mathrm{MW}$} & $150 \mathrm{M} €$ \\
\hline & $5(2 \mathrm{GW})$ & & $300 \mathrm{M} €$ \\
\hline \multicolumn{3}{|c|}{ Total Cost to transmit $3 \mathrm{GW}$} & $3404 \mathrm{M} €$ \\
\hline \multicolumn{3}{|c|}{ Total Cost per GW } & $1135 \mathrm{M} € / \mathrm{GW}$ \\
\hline
\end{tabular}

\section{Radial 3+3 DC grid with hybrid DC CBs}

The hybrid DC circuit breakers have been demonstrated by at least two manufacturers and the performance of a single component is very good [10]. The selective, fast and reliable DC protection systems however have not been developed and the need for communication across large DC grids may become a big issue.

We now try to develop a topology that uses only local sensor signals for DC CB tripping, enabling DC CBs to operate fast and in isolation. The trip decision is made independently at each DC CB based only on the local fault current magnitude and direction. Figure 5 shows $3+3$ terminals DC grid with central DC bus and hybrid DC CBs. A back-up protection is also employed in this topology by using a split configuration for the central DC bus. This topology has much better technology readiness and reliability than topology 2 since communication between DC CBs or protection selectivity is not required. 


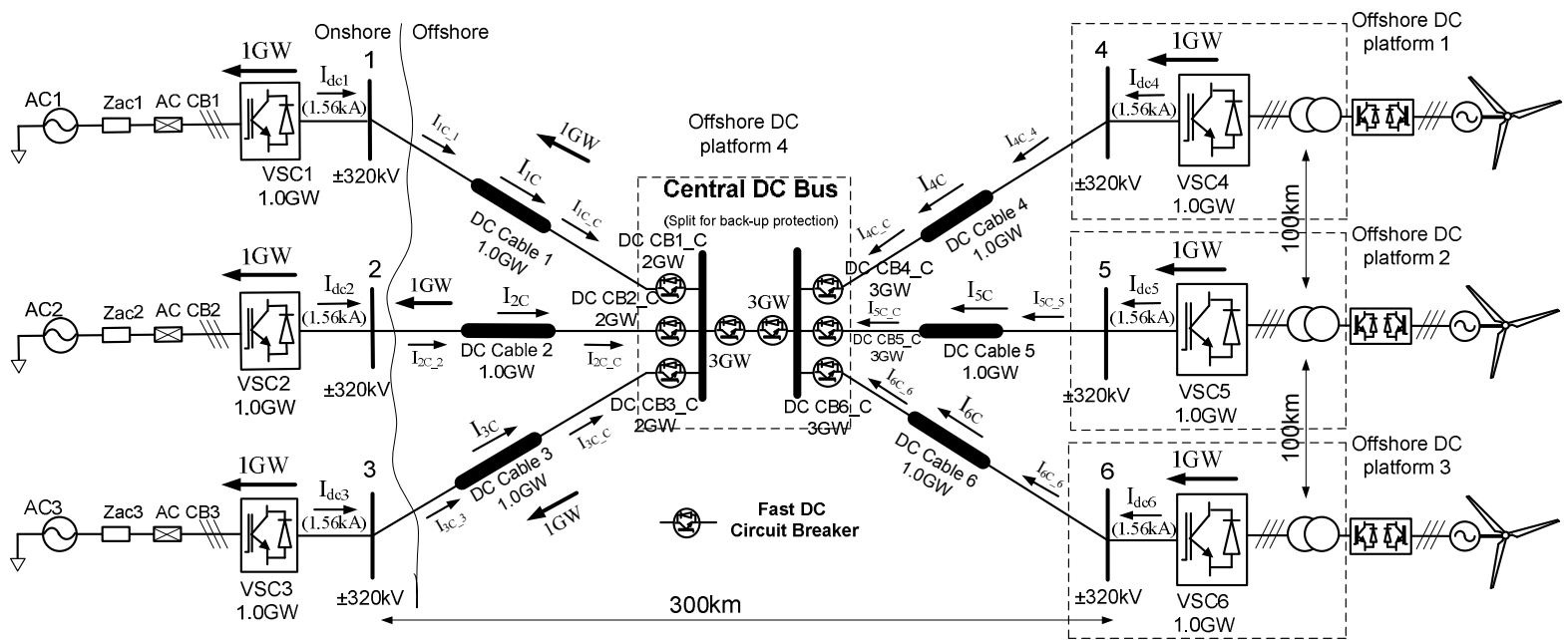

Figure 5. $\quad 3+3$ terminals radial DC grid with optimal capacity (topology 3 )

In this topology, for any DC cable fault only one DC CB (and back up DC CB at split bus) will see positive DC current and therefore discrimination/selection is very simple. A DC fault is isolated with one DC CB and one AC CB. The AC CB operates similarly as with DC faults on any HVDC link. In practice the above DC grid topology can be developed using only one star point. However multiple local star-grids can be interconnected into a large DC grid using DC/DC converters.

The challenge with this topology, when compared with topology 2, is that DC CBs will take even higher fault currents. Each DC CB in topology 3 will take DC fault current from $p$ - 1 VSCs, where $\mathrm{p}$ is the number of VSCs connected to the bus, but in the particular test system the 3 VSCs from offshore terminals are capable of limiting DC fault current. Therefore the required rating for bus-bar DC CBs will be $3.0 \mathrm{GW}$ while for the DC CBs facing onshore VSC it will be $2.0 \mathrm{GW}$, and the DC CBs facing wind farms are rated for 3GW since they might take DC fault current from all 3 onshore VSCs. The number of VSC converters connecting to the central DC bus and possible expansion will be limited by the rating of DC CBs. Adding new radial lines might require uprating all DC CBs. However the length of DC lines has no impact on protection operation.

Table 5 shows current levels in each DC cable during cables fault, and prior to fault isolation. The notation $I_{d c \_ \text {rated }}$ means nominal current (1kA).

Table 5: topology 3 variables for cables fault

\begin{tabular}{|l|l|l|}
\hline \multicolumn{3}{|c|}{ Fault on the cable } \\
\hline Fault current & Cable 1C & Cable 4C \\
\hline Cable 1 (I1C) & $\begin{array}{l}\text { I1C_1 = 1fpu, } \\
\text { I1C_C } \approx \text { 2fpu }\end{array}$ & $\begin{array}{l}\text { I1C_1 = 1fpu, } \\
\text { I1C_C = 1fpu }\end{array}$ \\
\hline Cable 2 (I2C) & $\begin{array}{l}\text { I2C_2 = 1fpu, } \\
\text { I2C_C = 1fpu }\end{array}$ & $\begin{array}{l}\text { I2C_2 = 1fpu, } \\
\text { I2C_C = 1fpu }\end{array}$ \\
\hline
\end{tabular}




\begin{tabular}{|l|l|l|}
\hline Cable 3 (I3C) & $\begin{array}{l}\text { I3C_3 = 1fpu, } \\
\text { I3C_C = 1fpu }\end{array}$ & $\begin{array}{l}\text { I3C_3 = 1fpu, } \\
\text { I3C_C = 1fpu }\end{array}$ \\
\hline Cable 4 (I4C) & $\begin{array}{l}\text { I4C_4 = Idc4_rated, } \\
\text { I4C_C = Idc4_rated }\end{array}$ & $\begin{array}{l}\text { I4C_4 = Idc4_rated, } \\
\text { I4C_C } \approx \mathbf{3 f p u}\end{array}$ \\
\hline Cable 5 (I5C) & $\begin{array}{l}\text { I5C_5 = Idc5_rated, } \\
\text { I5C_C = Idc5_rated }\end{array}$ & $\begin{array}{l}\text { I5C_5 = Idc5_rated, } \\
\text { I5C_C = Idc5_rated }\end{array}$ \\
\hline Cable 6 (I6C) & $\begin{array}{l}\text { I6C_6 = Idc6_rated, } \\
\text { I6C_C = Idc6_rated }\end{array}$ & $\begin{array}{l}\text { I6C_6 = Idc6_rated, } \\
\text { I6C_C = Idc6_rated }\end{array}$ \\
\hline
\end{tabular}

After each DC fault clearance there will be loss in capacity of $1 \mathrm{GW}$.

Table 6 shows cost estimation of the major components of this topology, and the total cost per GW is only few percents larger than topology 2 .

Table 6: Cost estimation for the topology 3

\begin{tabular}{|c|c|c|c|}
\hline Items & Numbers and Rated & Cost estimation $\mathrm{M} € /$ unit & Cost estimation \\
\hline AC station with all equipments & $3(1 \mathrm{GW})+3(1 \mathrm{GW})$ & 110 & $660 \mathrm{M} €$ \\
\hline Offshore VSC platform 1-3 & VSC & 150 & $450 \mathrm{M} €$ \\
\hline Offshore VSC platform 4 & $3 \times$ DC CB $(2 \mathrm{GW})+5 \times$ DC CB $(3 \mathrm{GW})$ & $3 \times 40.6+5 \times 60.9$ & $426 \mathrm{M} €$ \\
\hline \multirow{4}{*}{ DC Cable (pair) } & $1(1 \mathrm{GW}, 150 \mathrm{~km})$ & \multirow{4}{*}{$0.0014 / \mathrm{km}$} & $210 \mathrm{M} €$ \\
\hline & $1(1 \mathrm{GW}, 150 \mathrm{~km})$ & & $210 \mathrm{M} €$ \\
\hline & $2(1 \mathrm{GW}, 180 \mathrm{~km})$ & & $504 \mathrm{M} €$ \\
\hline & $2(1 \mathrm{GW}, 180 \mathrm{~km})$ & & $504 \mathrm{M} €$ \\
\hline \multirow{2}{*}{ Hybrid DC circuit breaker } & $3(2 \mathrm{GW})$ & \multirow{2}{*}{$0.03 / \mathrm{MW}$} & $180 \mathrm{M} €$ \\
\hline & $5(3 \mathrm{GW})$ & & $450 \mathrm{M} €$ \\
\hline \multicolumn{3}{|c|}{ Total Cost to transmit $3 \mathrm{GW}$} & $3594 \mathrm{M} €$ \\
\hline \multicolumn{3}{|c|}{ Total cost per GW } & $1198 \mathrm{M} € / \mathrm{GW}$ \\
\hline
\end{tabular}

\section{Meshed 3+3 DC grid with DC/DC converters}

Figure 6 shows the proposed DC grid topology exploiting benefits of DC/DC converters. The nominal power flow and component ratings are also shown in the figure. The DC/DC converters can limit and control the fault current, and the rating is independent on DC fault levels. On the downside the cost and losses are high. Each meshed line includes a DC/DC converter on one end and a hybrid DC CB on the other end. Theoretically, any number of further DC lines between any terminals can be added if this principle is followed. However the most cost-effective topologies are achieved if a small number of meshed lines with DC/DC converters is located strategically to separate local DC grids. The DC/DC converters in this topology will segment the DC grid in independent protection zones. Each hybrid DC CB therefore can operate on the local overcurrent signal, since in no case will two DC CBs see fault current simultaneously.

The main advantages are: 1) In case of DC faults there will be only local DC voltage collapse spreading to two VSCs (there will not be DC voltage collapse across whole DC grid), 2) there will be only local DC fault current of high magnitude from one VSC. Each hybrid DC CB will take fault current from only one VSC and each DC CB can trip very fast (1-2ms) using only local current sensor. 
The mechanical DC CBs are used on DC lines which have very low DC fault current (approximately zero) and where fast fault clearing is not essential (i.e. DCCB 14_4). If all DC grid terminals are high power VSC converters (no wind farms) then these mechanical DC CBs should be replaced with hybrid DC CBs.

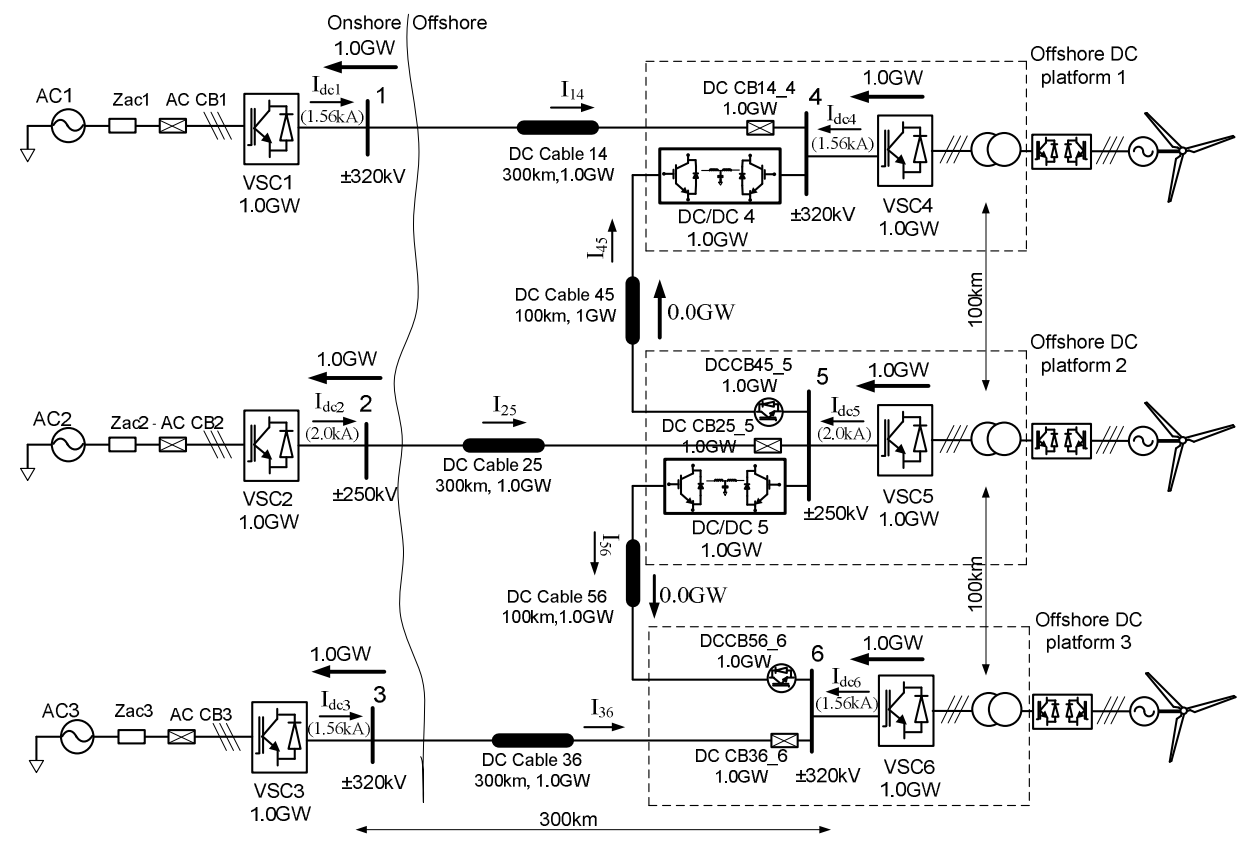

Figure $6 . \quad 3+3$ terminals DC grid topology with DC/DC converters (topology 4)

Table 7 shows current levels in each DC cable during cables fault, and prior to fault isolation. We can see that DC faults on any cable cause only local current rise and voltage collapse. We can also see that in case of faults on cables 45 and 56 the DC CBs on corresponding lines will take high fault currents coming from only one of the terminals 2 or 3 .

Table 7: Topology 4 DC grid variables for DC cable faults

\begin{tabular}{|c|c|c|}
\hline & \multicolumn{2}{|l|}{ Fault on the cable } \\
\hline Fault current & Cable 14 & Cable 45 \\
\hline Cable 14 (I14) & $\begin{array}{l}\mathrm{I} 14 \_1=1 \mathrm{fpu} \\
\mathrm{I} 14 \_4 \approx \mathrm{Idcdc} \text { rated }\end{array}$ & $\begin{array}{l}\mathrm{I} 14 \_1=\mathrm{Idc} 1 \text { rated } \\
\mathrm{I} 14-4=\mathrm{Idc} 1 \text { rated }\end{array}$ \\
\hline Cable 25 (I25) & $\begin{array}{l}\mathrm{I} 25 \_2=\mathrm{Idc} 2 \text { rated } \\
\mathrm{I} 25[5=\mathrm{Idc} 2 \text { rated }\end{array}$ & $\begin{array}{l}\mathrm{I} 25 \_2=1 \mathrm{fpu} \\
\mathrm{I} 2555=1 \mathrm{fpu}\end{array}$ \\
\hline Cable 36 (I36) & $\begin{array}{l}\text { I36_3 }=\text { Idc3_rated, } \\
\text { I36_6 }=\text { Idc3_rated }\end{array}$ & $\begin{array}{l}\text { I36_3 }=\text { Idc3_rated, } \\
\text { I36_6 }=\text { Idc3_rated }\end{array}$ \\
\hline Cable 45 (I45) & $\begin{array}{l}\text { I45_4 } \approx \text { Idcdc_rated, } \\
\text { I45 } 5 \approx \text { Idcdc_rated }\end{array}$ & $\begin{array}{l}\text { I45_4 } \approx \text { Idcdc_rated } \\
\text { I45_5 } \approx 1 \mathrm{fpu}\end{array}$ \\
\hline Cable 56 (I56) & $\begin{array}{l}\text { I56_5 } \approx \text { Idcdc_rated, } \\
\text { I56_6 } \approx \text { Idcdc_rated }\end{array}$ & $\begin{array}{l}\text { I56_5 } \approx \text { Idcdc_rated } \\
\text { I56_6 } \approx \text { Idcdc rated }\end{array}$ \\
\hline
\end{tabular}

After a fault on cable 14, 25 and 36 there will be $1.0 \mathrm{GW}$ loss in capacity and the grid can only transfer up to $2 \mathrm{GW}$, similarly as in previous topologies. After a fault on cable 45 or 56 there is no loss in capacity but system would move to "alert state". 
Table 8 shows cost estimation of the major components, and the total cost is only marginally above costs for topology 2 or 3 . The reason for modest overall costs is that we only need two DC/DC converters with optimal rating. Note also that on-state losses with topology 4 are very small and similar with topology 2 or 3 while power is not routed through DC/DC converters, otherwise each DC/DC converter will consume around $2 \%$ in losses. The expansion can be achieved following the same grid architecture.

Table 8: Cost estimation for topology 4, (DC grid with DC/DC and optimal ratings)

\begin{tabular}{|c|c|c|c|}
\hline Items & Numbers and Rated & Cost estimation M€/unit & Cost estimation \\
\hline $\mathrm{AC} / \mathrm{DC}$ VSC converter & $3(1.0 \mathrm{GW})+3(1.0 \mathrm{GW})$ & 110 & $660 \mathrm{M} €$ \\
\hline Offshore VSC platform 1 & $\mathrm{VSC}+1 \times \mathrm{DC} \mathrm{DC}(1 \mathrm{GW})$ & $150+197$ & $347 \mathrm{M€}$ \\
\hline Offshore VSC platform 2 & $\mathrm{VSC}+1 \times \mathrm{DC} D C(1 \mathrm{GW})+1 \times \mathrm{DC} C \mathrm{CB}(1 \mathrm{GW})$ & $150+197+20.3$ & $367 \mathrm{M} €$ \\
\hline Offshore VSC platform 2 & VSC $1 \times$ DC CB $(1 \mathrm{GW})$ & $150+20.3$ & $170 \mathrm{M} €$ \\
\hline \multirow{2}{*}{ DC cable (pair) } & $3(1.0 \mathrm{GW}, 300 \mathrm{~km})$ & \multirow{2}{*}{$0.0014 / \mathrm{km}$} & $1260 \mathrm{M} €$ \\
\hline & $2(1 \mathrm{GW}, 100 \mathrm{~km})$ & & $280 \mathrm{M} €$ \\
\hline Mechanical DC/CB & $3(1.0 \mathrm{GW})$ & $0.0003 / \mathrm{MW}$ & $0.9 \mathrm{M} €$ \\
\hline Hybrid DC/CB & $2(1.0 \mathrm{GW})$ & $0.03 / \mathrm{MW}$ & $60 \mathrm{M} €$ \\
\hline DC/DC IGBT based converter & $2(1 \mathrm{GW})$ & $0.18 / \mathrm{MW}$ & $360 \mathrm{M} €$ \\
\hline \multicolumn{3}{|c|}{ Total Cost to transmit 3GW } & $3505 \mathrm{M} €$ \\
\hline \multicolumn{3}{|c|}{ Total cost per GW } & $1168 \mathrm{M} € / \mathrm{GW}$ \\
\hline
\end{tabular}

\section{3+3 DC grid with a DC hub}

The DC hub can be viewed as a multiport version of DC/DC converters, which can also be viewed as an isolated AC grid with multiple HVDC infeeds. It is considerably more cost effective than multiple DC/DC converters when numerous DC lines connect to the same DC bus. It is important to note that each port in the hub can be permanently isolated using a local AC CBs which connects to the central AC bus inside the hub [9].

Figure 7 shows proposed DC grid topology connecting same 6 VSC converters through a six-port DC-hub. There is no limit on the number of DC lines that can be connected to the hub and therefore this topology is most suitable for expansion. One VSC terminal is purposely chosen with different DC voltage rating $(250 \mathrm{kV})$ to illustrate flexibility of the hub to connect multivendor DC systems, from different manufacturers. The main advantages of this topology are:

- Opportunity for power trading between any VSC terminals. Power trading to full VSC terminal rating is possible at any time.

- Infinite expansion. Any number of DC lines of any rating can be connected to the DC hub (a new port is required for new line).

- A fault on any DC line is readily isolated. There will be no disturbance to other DC lines and terminals. There is no need for fast protection systems or controls and no high currents will be present. The rating is not dependent on fault levels.

- $\quad$ Each DC line can have different voltage rating and different control/technology.

The main shortcomings are:

- There will be continuous conduction loss through the DC hub, perhaps around $2 \%$, between any two terminals. This implies $6 \%$ total loss at full power. 


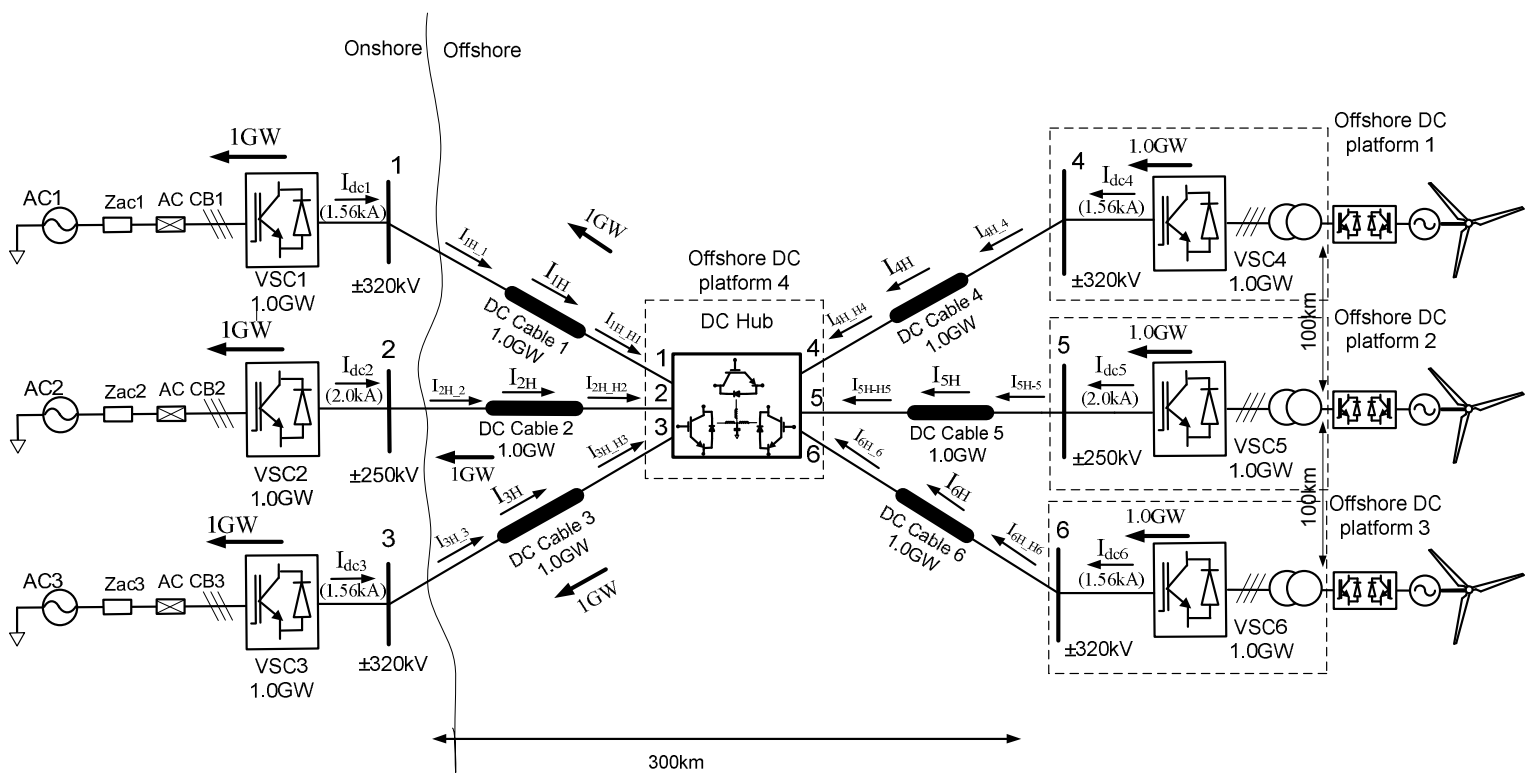

Figure 7. 3 onshore VSCs connected with 3 offshore wind farms through a DC-hub (topology 5)

The performance of the grid under a dc fault can be analyzed similarly as with DC/DC converters. After a fault on any cable and successful clearance, there will be $1 \mathrm{GW}$ loss in capacity. As an example, for a cable $1 \mathrm{H}$ fault, AC circuit breaker "AC CB1" will open and isolates terminal 1 from the hub. The hub will internally open AC circuit breaker associated with the faulted port.

Table 9 shows $1223 \mathrm{M} €$ as total cost per GW, which is $8 \%$ higher than the lowest cost topology 2 .

Table 9: Cost estimation for the topology 5

\begin{tabular}{|c|c|c|c|}
\hline Items & Numbers and Rated & Cost estimation $\mathrm{M} € /$ unit & Cost estimation \\
\hline AC station with all equipments & $3(1 \mathrm{GW})+3(1 \mathrm{GW})$ & 110 & $660 \mathrm{M} €$ \\
\hline Offshore platforms 1-3 & $\operatorname{VSC}(1 \mathrm{GW})$ & 150 & $450 \mathrm{M€}$ \\
\hline Offshore platform 4 & $1 \times$ DC Hub, 6 ports & 98.4 /port & $590 \mathrm{M} €$ \\
\hline \multirow{4}{*}{ DC Cable (pair) } & $1(1 \mathrm{GW}, 150 \mathrm{~km})$ & \multirow{4}{*}{$0.0014 / \mathrm{km}$} & $210 \mathrm{M} €$ \\
\hline & $1(1 \mathrm{GW}, 150 \mathrm{~km})$ & & $210 \mathrm{M} €$ \\
\hline & $2(1 \mathrm{GW}, 180 \mathrm{~km})$ & & $504 \mathrm{M€}$ \\
\hline & $2(1 \mathrm{GW}, 180 \mathrm{~km})$ & & $504 \mathrm{M} €$ \\
\hline DC-Hub (IGBT-based converter) & $1(1 \mathrm{GW}), 6$ ports & $0.09 \mathrm{M€} / \mathrm{MW}$ (per port) & $540 \mathrm{M} €$ \\
\hline \multicolumn{3}{|c|}{ Total Cost to transmit $3 \mathrm{GW}$} & $3668 \mathrm{M€}$ \\
\hline \multicolumn{3}{|c|}{ Total cost per GW } & $1223 \mathrm{M} € / \mathrm{GW}$ \\
\hline
\end{tabular}

\section{Conclusion}

This article have selected 4 different DC grid topologies using different protection methods for connecting $31 \mathrm{GW}$ offshore wind farms with $31 \mathrm{GW}$ onshore VSC terminals and compared with the base case of 3 HVDC systems. Table 10 summariss the overall comparison of the topologies.

Considering the total costs, it is concluded that capital investment for all topologies is similar (within 8\%). Although individual costs for DC hub and DC/DC converter are high, they effectively isolate DC faults and therefore the number of units is small and their rating is low. In case of topologies with hybrid DC CBs the number of units is large and some units should have high rating since high 
fault currents can add together from multiple DC terminals. The study demonstrates that a lot of uncertainty exists with hybrid DC CB considering required ratings and grid wide protection systems, but also line lengths and expansion possibilities are limited.

Comparing with the basic case of $3 \mathrm{HVDC}$, we see that in all cases developing a DC grid demands approximately $50 \%$ cost increase. However large part of this additional cost is related to new DC cables which increase operating flexibility and power security.

Finally, it can be concluded that the best topology for DC grid could be a combination of strategically located DC hubs or DC/DC converters together with hybrid DC CBs employed in isolation on local, radial DC lines.

Table 10. Final comparison of 5 topologies

\begin{tabular}{|c|c|c|c|c|c|}
\hline & $\begin{array}{l}\text { Topology } 1 \\
\text { (3 HVDC) }\end{array}$ & $\begin{array}{l}\text { Topology } 2 \\
\text { (Meshed DC CBs) }\end{array}$ & $\begin{array}{l}\text { Topology } 3 \\
\text { (Star DC CBs) }\end{array}$ & $\begin{array}{l}\text { Topology } 4 \\
\text { (Meshed DC/DC) }\end{array}$ & $\begin{array}{l}\text { Topology } 5 \\
\text { (DC hub) }\end{array}$ \\
\hline Capital investment & $790 \mathrm{M} € / \mathrm{GW}$ & $1135 \mathrm{M} € / \mathrm{GW}$ & $1198 \mathrm{M} € / \mathrm{GW}$ & $1168 \mathrm{M} € / \mathrm{GW}$ & $1223 \mathrm{M} € / \mathrm{GW}$ \\
\hline $\begin{array}{l}\text { Loss in capacity for } \\
\text { a DC cable fault }\end{array}$ & $2 \mathrm{GW}$ & $\begin{array}{l}1 \mathrm{GW} \text { for fault on } \\
\text { cables } 1415 \text { or } 36 \text {, } \\
0 \mathrm{GW} \text { for fault on } \\
45 \text { or } 56 .\end{array}$ & $1 \mathrm{GW}$ & $\begin{array}{l}1 \mathrm{GW} \text { for fault on } \\
\text { cables } 1415 \text { or } 36 \text {, } \\
0 \mathrm{GW} \text { for fault on } \\
45 \text { or } 56 .\end{array}$ & $1 \mathrm{GW}$ \\
\hline Expansion & Not feasible & $\begin{array}{l}\text { Requires uprating } \\
\text { all DC CBs }\end{array}$ & $\begin{array}{l}\text { Requires uprating } \\
\text { all DC CBs }\end{array}$ & unlimited & unlimited \\
\hline DC cable length & Any length & $\begin{array}{l}\text { Long cables require } \\
\text { uprating } \mathrm{DC} \mathrm{CBs}\end{array}$ & Any length & Any length & Any length \\
\hline $\begin{array}{l}\text { Transmission losses } \\
\text { at full power }\end{array}$ & $\begin{array}{l}\text { Negligible } \\
\text { (DC cable loss) }\end{array}$ & $\begin{array}{l}\text { Negligible } \\
\text { (DC cable loss) }\end{array}$ & $\begin{array}{l}\text { Negligible } \\
\text { (DC cable loss) }\end{array}$ & $\begin{array}{l}\text { Negligible }(2 \% \text { if } \\
\text { power is routed } \\
\text { through } \quad \mathrm{DC} / \mathrm{DC} \\
\text { inertie })\end{array}$ & $\begin{array}{l}6 \% \text { plus } \\
\text { DC cable loss }\end{array}$ \\
\hline $\begin{array}{l}\text { Multivendor DC } \\
\text { grid }\end{array}$ & No & Difficult & Difficult & Possible & Possible and simple \\
\hline
\end{tabular}

\section{Acknowledgment}

We are thankful to RTE for financial support of this project. 


\section{$4 \quad$ References}

[1] J. Descloux, P. Rault, S. Nguefeu, J-B Curis, X. Guillaud, F. Colas, and B. Raison, "HVDC meshed grid: Control and protection of a multiterminal HVDC system”, CIGRE B4-308, general assembly 2012, France

[2] M. Taherbaneh, D. Jovcic, J.P. Taisne and S. Nguefeu, "DC Fault Performance and Cost Analysis of DC Grids for Connecting Multiple offshore Wind Farms," Powertech, Grenoble, June 2013

[3] K. Bell, D. Cirio, A.M. Denis, L. He, C. C. Liu, G. Migliavacca, C. Moreira, and P. Panciatici, "Economic and technical criteria for designing future off-shore HVDC grids," Innovative Smart Grid Technologies Conference Europe (ISGT Europe), 2010 IEEE PES

[4] R.S. Whitehouse, "Technical Challenges of Realising Multi-terminal Networking with VSC," Proceedings of the $14^{\text {th }}$ European Conference on Power Electronics and Applications (EPE 2011), Birmingham, Sep. 2011.

[5] J. Descloux, B. Raison and J-B Curis, "Protection strategy for undersea MTDC grids," Powertech 2013, Grenoble, June 2013.

[6] J. HÄFNER and B. JACOBSON, "Proactive Hybrid HVDC Breakers - A key innovation for reliable HVDC grids," CIGRE 2011 Bologna Symp., Bologna, Italy, paper 264, Sep. 2011.

[7] B. Bachmann, "Development of a $500 \mathrm{kV}$ airblast HVDC circuit breaker", IEEE Transactions on Power Aparatus and Systems, Vol. PAS-104, No.9, Sept. 1985 pp. $2460-2466$.

[8] D Jovcic, L Zhang and M Hajian, "LCL VSC converter for High power applications ” IEEE Transactions on Power Delivery, Vol 28, January 2013,pp 137-145.

[9] D. Jovcic, W. Lin, "Multiport high power LCL DC hub for use in DC Transmission Grids" IEEE Transactions on Power Delivery, Vol 29, iss 2, 2014, pp 760-768.

[10] ENTSOE, “Offshore Transmission Technology," Report by regional group north sea for the NSCOGI, November 2011, https://www.entsoe.eu/publications/system-development-reports/north-seas-grid-development/

[11] CIGRE working group B4.52 "Feasibility of DC grids" CIGRE Brochure 533, 2013.

[12] Kundur,P “Power System Stability and Control” McGraw Hill, Inc 1994.

[13] F. Deng, and Z. Chen, "Design of Protective Inductors for HVDC Transmission Line Within DC Grid Offshore Wind farms", IEEE Transaction on Power Delivery, Vol. 28, No. 1, January 2013.

[14] Junyent-Ferre, A.; Prieto-Araujo, E.; Gomis-Bellmunt, O.; Bianchi, F., "Voltage sag ridethrough of PMSG wind turbines using droop control stabilization," European Conference on Power Electronics and Applications (EPE 2011), vol., no., pp.1,8, Aug. 302011 -Sept. 12011 